\title{
INTERACTION EFFECTS OF TEACHERS' EDUCATIONAL POLICY AND STUDENTS' LEARNING GOAL ORIENTATION ON STUDENTS' LEARNING-AS-DUTY CONCEPTION
}

\author{
Mai Yokoyama and Kazuhisa Miwa \\ Nagoya University, Japan
}

\begin{abstract}
In order to clarify the effects of teachers' Educational Policy on students' Learning-as-duty Conception, we examined the effects of interaction between teachers' Educational Policy and students' Learning Goal Orientation on Learning-as-duty Conception of the students. A questionnaire survey was conducted with 50 teachers and 189 undergraduate students at a Japanese public university. The interaction between teachers' Educational Policy and students' Learning Goal Orientation showed a significant or a marginally significant for students' Learning-as-duty Conception in five of twelve cases. The findings suggested that the relationship between teachers' Educational Policy and students' Learning-as-duty Conception may change depending on the level of students' Learning Goal Orientation.
\end{abstract}

\section{KEYWORDS}

Educational Policy, Learning Goal Orientation, Learning-as-duty Conception

\section{INTRODUCTION}

\subsection{Learning-as-duty Conception}

There are differences in students' learning behavior, depending on their conception of learning. Van Rossum and Schenk (1984) suggested that students who perceived learning as memorizing adopted superficial learning behavior, whereas those who perceived learning as the abstraction of meaning or interpretative processes aimed at the understanding of reality adopted deep learning behavior. Furthermore, Dart et al. (2000) showed that students who held qualitative conceptions such as personal fulfillment and experiential conceptions not bounded by time were more likely to utilize deep approaches to learning, whereas students who held quantitative conceptions, such as an increase of knowledge, were more likely to rely on superficial approaches.

In this study, we focus particularly on "Learning-as-duty Conception." It is widely known that such a conception negatively affects learning behavior. Peterson et al. (2010) argued that Learning-as-duty Conception has a negative effect on academic achievement. Furthermore, Takayama (2002) revealed that Learning-as-duty Conception is a factor that promotes superficial learning behavior.

\subsection{Learning Goal Orientation}

The individual characteristics for student goals in learning are called goal orientation. It is known that goal orientation is broadly divided into Learning Goal Orientation and performance goal orientation. In this study we focus on Learning Goal Orientation. The learning goal is the goal to acquire new knowledge and skills through challenging activities, and it has been clarified as promoting positive learning behavior. Students who are oriented toward learning goals tend to persevere even when they encounter failure (Diner \& Dweck 1978) and deliberately select challenging tasks (Elliot \& Dweck 1988). According to Ames and Archer 
(1987, 1988), Learning Goal Orientation has a positive effect on both academic achievement and endogenous motivation.

It has been revealed that there are differences in educational support effects, depending on the level of the students' Learning Goal Orientation. For example, Walter et al. (2005) showed that the effect of teacher feedback on students' learning behavior is contingent on the level of the student's Learning Goal Orientation. Patrick et al. (2011) also suggested that the effect of parental support on students' self-efficacy depends on the level of the students' Learning Goal Orientation.

\subsection{Factors that Suppress Learning-as-duty Conception}

Yokoyama and Miwa (2018) examined the cause-and-effect relationships of goal orientation, learning conception and learning behavior. The results of the study are consistent with the results of Peterson et al. (2010) and Takayama (2002), suggesting that Learning-as-duty Conception inhibits positive learning behavior. In this context, we have a question of how to suppress Learning-as-duty Conception that negatively affects learning behavior. Yokoyama and Miwa (2018) suggested that Learning Goal Orientation can be a factor in suppressing Learning-as-duty Conception. Although the study revealed students' internal factors, such as Learning Goal Orientation, that suppress Learning-as-duty Conception, external factors, such as teachers' intervention, were not examined. We need further study to examine external factors in order to provide educational support to suppress students' Learning-as-duty Conception. One of the external factors is teachers' intervention, which is guided by teachers' Educational Policy. We assumed that teachers' Educational Policy may change students' Learning-as-duty Conception.

\subsection{Purpose}

Figure 1 shows the outline of this study. The purpose of this study is to examine the effects of teachers' Educational Policy on students' Learning-as-duty Conception. We assume that the effects may depend on students' Learning Goal Orientation. Yokoyama and Miwa (2018) confirmed the negative correlation between students' Learning Goal Orientation and Learning-as-duty Conception in Figure 1. In this study, in order to clarify the effects of teachers' Educational Policy on students' Learning-as-duty Conception, we examined the interaction effects between teachers' Educational Policy and students' Learning Goal Orientation on Learning-as-duty Conception of the students. It is expected that the effects of teachers' Educational Policy on students' Learning-as-duty Conception will vary depending on the level of the students' Learning Goal Orientation.

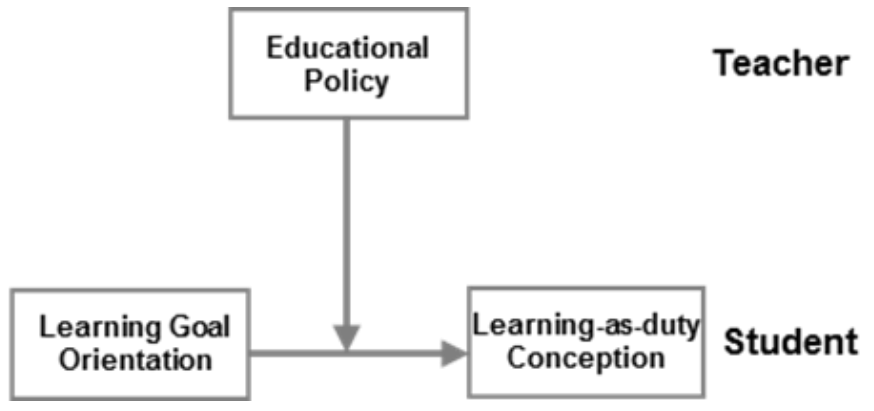

Figure 1. Outline of this study

In this study, we examined such effects in seminar classes consisting of single teacher and a small group of students. The content and methods of seminar classes are usually chosen at the teachers' discretion and thus, each class reflects their Educational Policy. In addition, since the seminar classes are conducted with a small number of students during one or two years through the relatively long term of classes, the teacher-student relationship is expected to become deeper than in general classes. These conditions imply that teachers' Educational Policy of seminars greatly affects students' Learning-as-duty Conception. 


\section{METHOD}

\subsection{Method of Survey}

The class practice was conducted in the School of Integrated Arts and Sciences of a Japanese public university. A questionnaire survey was conducted with 50 university teachers who had taught in seminar classes for two years, and 189 undergraduate students who had participated in the seminar classes during the third to fourth grade from 2017 to 2018 . The seminars were among the compulsory subjects, and took more than 180 minutes a week. The survey was conducted from February to March 2019.

\subsection{Measures}

\section{For teachers}

Educational Policy: The following five categories of items, developed by Fushikida et al. (2014), were used in a comprehensive questionnaire to measure the teachers' Educational Policy of running seminars. (A) Understanding Students' Characteristics (6 items); (B) Educational Goals (7 items); (C) Learning Goals (12 items), (D) Learning Activities (12 items); and (E) Teachers' Instructions (11 items). Each item was rated on a 5-point scale.

\section{For students}

Learning-as-duty Conception: Five items from the "Duty and Memorizing" factor in Yokoyama and Miwa (2018), modified from Takayama's (2002) learning conception scale (e.g., "Learning is being forced by parents or teachers." "Learning is being forced to do things that you do not want to do.") were rated on a 5-point scale.

Learning Goal Orientation: Four items from the "Learning Goal" factor in Yokoyama and Miwa (2018), translated from Elliot and Church's (1997) Achievement Goal Scale (e.g., "I hope to have gained a broader and deeper knowledge when I am done with classes." "I want to learn as much as possible from classes.") were rated on a 5-point scale.

\subsection{Method of Analysis}

The answers from teachers to evaluate their Educational Policy of the seminar are group level (the seminar level) data, while those from students to evaluate Learning-as-duty Conception and Learning Goal Orientation are individual level data. Therefore, hierarchical linear model analysis was performed. The dependent variable was the Learning-as-duty Conception, and the independent variables were the Learning Goal Orientation and the teachers' Educational Policy of the seminar. We calculated the intra-class correlation coefficient (ICC) of Learning Goal Orientation and Learning-as-duty Conception to evaluate intra-group similarity. If the value of ICC indicated .10 or more, it was judged that the answers among students for the same seminar were consistent, and the average value of Learning Goal Orientation for each seminar was able to be utilized for the model as variable. We excluded the data in the seminar consisting of a single student. As a result, the data of 43 seminars, including 43 teachers and 179 students, were analyzed.

\section{STRUCTURE OF THE SCALES}

\subsection{Teachers' Educational Policy of the Seminar}

The $\alpha$ coefficients calculated based on the factor structure of Fushikida et al. (2014) were extremely low. Therefore, we performed exploratory factor analysis again (principal factor with promax rotation) for each of the five categories. Items that were loaded at .35 or less and items that were loaded at .35 or more on two or more factors, were excluded. The factor category was decided from the items with high factor loading. An average value of the items was regarded as a representative value of each factor. 
As a result of factor analysis of (A) Understanding Students' Characteristics, one factor emerged. The factor and sample items are: (A1) Understanding Students' Characteristics (5 items; $\alpha=.61$ ), "Cognitive proficiency" "Interest in learning."

As a result of factor analysis of (B) Educational Goals, two factors emerged. The factors and sample items are: (B1) Goals to Enhance Seminar Activities (4 items; $\alpha=.71$ ), "Introduce the latest research development" "Strengthen the relationship between teachers and students, and among students"; and (B2) Goals to Promote Student Growth ( 2 items; $\alpha=.52$ ), "Lead students to growth." Since the $\alpha$ coefficient is small, the second factor was excluded from further analysis.

As a result of factor analysis of (C) Learning Goals, three factors emerged. The factors and sample items are: (C1) Goals to Improve Inquiring Mind (4 items; $\alpha=.79$ ), 'Improve students' motivation to learn" "Improve students' thinking skills"; (C2) Goals to Acquire Social Skills (3 items; $\alpha=.69$ ), "Students are aware of relationship with society" "Students acquire generic skills beyond their major"; and (C3) Achievement Goals of Specialization ( 3 items; $\alpha=.57$ ), "Students utilize acquired knowledge, skills and attitudes" "Students deepen their systematic understanding of learning content."

As a result of factor analysis of (D) Learning Activities, four factors emerged. The factors and sample items are: (D1) Collaborative Learning Outside the University (5 items; $\alpha=.88$ ), "Students do fieldwork (observation, survey, etc.) in groups" "Students carry out joint projects with outside parties (other universities, companies, regions, etc.)"; (D2) Students' Presentations (5items; $\alpha=.85$ ), "Students give a presentation on the progress of the given task" "Students give a presentation on what they have investigated for a subject"; and (D3) Knowledge Transfer by Teachers (2 items; $\alpha=.65$ ), "Teacher gives a lecture"; and (D4) Discussion Between Teachers and Students ( 2 items; $\alpha=.65)$, "Students discuss among themselves."

As a result of factor analysis of (E) Teachers' Instructions, three factors emerged. The factors and sample items are (E1) Support for Task Execution (5 items; $\alpha=.77$ ), "Advise on theme settings" "Show clear goals to be achieved." (E2) Formative Evaluation of Presentation (4 items; $\alpha=.75$ ), "Evaluate content of the presentation" "Evaluate skills of the presentation"; and (E3) Teaching on References (2 items; $\alpha=.75$ ), "Give advice on reading literature."

\subsection{Students' Learning-as-duty Conception and Learning Goal Orientation}

The internal consistency was confirmed by calculating $\alpha$ coefficients of five items of "Learning-as-duty Conception" $(\alpha=.84)$ and four items of "Learning Goal Orientation" $(\alpha=.74)$. Since a sufficient $\alpha$ value was confirmed, an average value was regarded as a representative value of each factor.

\section{RESULTS}

The ICC of Learning Goal Orientation was .12 ( $\mathrm{p}<.01)$, the ICC of Learning-as-duty Conception was .18 $(\mathrm{p}<.01)$, showing that the responses among students in an individual seminar were consistent. An average value of Learning Goal Orientation in each seminar was treated as a representative variable of Learning Goal Orientation. The hierarchical linear model analysis was performed. Learning-as-duty Conception was defined as a dependent variable, and the teachers' Education Policy of the seminar and Learning Goal Orientation were defined as independent factors. The interaction of two independent factors was analyzed. We conducted 12 analyses, for each of which one of every 12 variables of teachers' Educational Policy of the seminar was used.

In all of the 12 analyses, Learning Goal Orientation showed significant negative effects on Learning-as-duty Conception. This result is consistent with the results of Yokoyama and Miwa (2018). In five analyses among those, the interaction between teachers' Educational Policy of the seminar and Learning Goal Orientation reached a significant or a marginally significant level (Table 1).

In order to examine the relationship between teachers' Educational Policy of the seminar and students' Learning-as-duty Conception, a simple slope test was conducted (Figure 2).

In the relationship between Understanding Students' Characteristics and Learning-as-duty Conception (Figure 2 (a)), in the seminar where the students have low Learning Goal Orientation, the slope was a significant positive value $(\beta=.25, \mathrm{p}<.01)$. This result showed that in the seminar consisting of students with low Learning Goal Orientation, the more the teacher tried to understand the students' characteristics, the higher the students' Learning-as-duty Conception became. 
Table 1. Results of Hierarchical Linear Model Analysis

\begin{tabular}{|c|c|c|c|c|c|c|c|c|c|}
\hline Variable & $\beta$ & Variable & $\beta$ & Variable & $\beta$ & Variable & $\beta$ & Variable & $\beta$ \\
\hline $\begin{array}{l}\text { Learning Goal } \\
\text { Orientation }\end{array}$ & $-.73 * *$ & $\begin{array}{l}\text { Learning Goal } \\
\text { Orientation }\end{array}$ & $-.81 * *$ & $\begin{array}{l}\text { Learning Goal } \\
\text { Orientation }\end{array}$ & $-.70 * *$ & $\begin{array}{l}\text { Learning Goal } \\
\text { Orientation }\end{array}$ & $-.77 * *$ & $\begin{array}{l}\text { Learning Goal } \\
\text { Orientation }\end{array}$ & $-.68 * *$ \\
\hline $\begin{array}{l}\text { Understanding } \\
\text { Students' } \\
\text { Characteristics } \\
\text { Interaction }\end{array}$ & $-.31+$ & $\begin{array}{l}\text { Goals to Enhance } \\
\text { Seminar } \\
\text { Activities } \\
\text { Interaction }\end{array}$ & $-.75^{* *}$ & $\begin{array}{l}\text { Goals to Acquire } \\
\text { Social Skills } \\
\text { Interaction }\end{array}$ & $\begin{array}{l}-.03 \\
-.53 *\end{array}$ & $\begin{array}{l}\text { Collaborative } \\
\text { Learning Outside } \\
\text { the University } \\
\text { Interaction }\end{array}$ & $-.38 * *$ & $\begin{array}{l}\text { Knowledge } \\
\text { Transfer by } \\
\text { Teachers } \\
\text { Interaction }\end{array}$ & $-.23+$ \\
\hline
\end{tabular}

In the relationship between Goals to Enhance Seminar Activities and Learning-as-duty Conception (Figure 2 (b)), in the seminar where the students have low Learning Goal Orientation, the slope was a significant positive value $(\beta=.25, \mathrm{p}<.01)$, while in the seminar where the students have high Learning Goal Orientation, the slope was a marginally significant negative value $(\beta=-.29, \mathrm{p}<.10)$. This result showed that in the seminar consisting of students with low Learning Goal Orientation, the more the teacher tried to improve seminar activities, the higher the students' Learning-as-duty Conception became. Conversely, in the seminar consisting of students with high Learning Goal Orientation, the more the teacher tried to improve seminar activities, the lower the students' Learning-as-duty Conception became.

In the relationship between Goals to Acquire Social Skills and Learning-as-duty Conception (Figure 2 (c)), in the seminar where the students have high Learning Goal Orientation, the slope was a marginally significant negative value $(\beta=-.22, \mathrm{p}<.10)$. This result showed that in the seminar consisting of high Learning Goal Orientation students, the more the teacher tried to get students to acquire social skills, the higher the students' Learning-as-duty Conception became.

In the relationship between Collaborative Learning Outside the University and Learning-as-duty Conception (Figure 2 (d)), in the seminar where the students have low Learning Goal Orientation, the slope was a marginally significant positive value $(\beta=.12, \mathrm{p}<.10)$, while in the seminar where the students have high Learning Goal Orientation, the slope was a significant negative value $(\beta=-.16, \mathrm{p}<.05)$. This result showed that in the seminar consisting of students with low Learning Goal Orientation, the more the teacher gave students the opportunity to experience collaborative learning outside the university, the higher the students' Learning-as-duty Conception became. Conversely, in the seminar consisting of students with high Learning Goal Orientation, the more the teacher gave students the opportunity to experience collaborative learning outside the university, the lower the students' Learning-as-duty Conception became.

In the relationship between Knowledge Transfer by Teachers and Learning-as-duty Conception (Figure 2 (e)), in the seminar where the students have low Learning Goal Orientation, the slope was a marginally significant positive value $(\beta=.12, \mathrm{p}<.10)$. This result showed that, in the seminar consisting of students with low Learning Goal Orientation, the more the teacher had the opportunity to transfer knowledge to the students, the higher the students' Learning-as-duty Conception became.

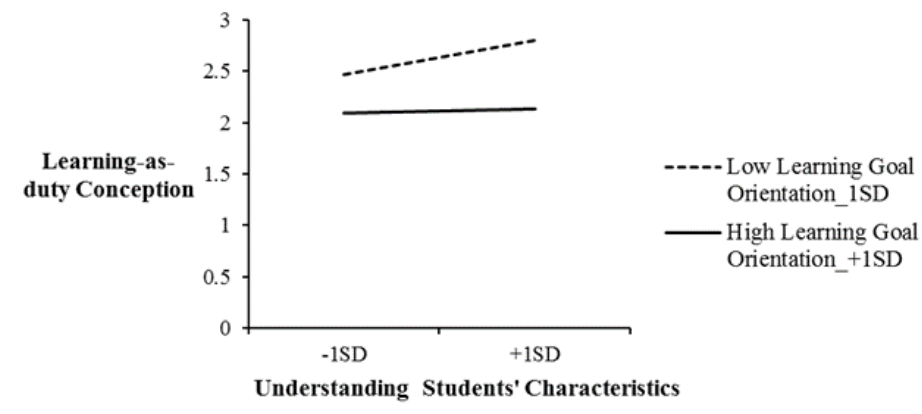

Figure 2(a). Interaction of Understanding Students' Characteristics and Learning Goal Orientation predicting Learningas-duty Conception 


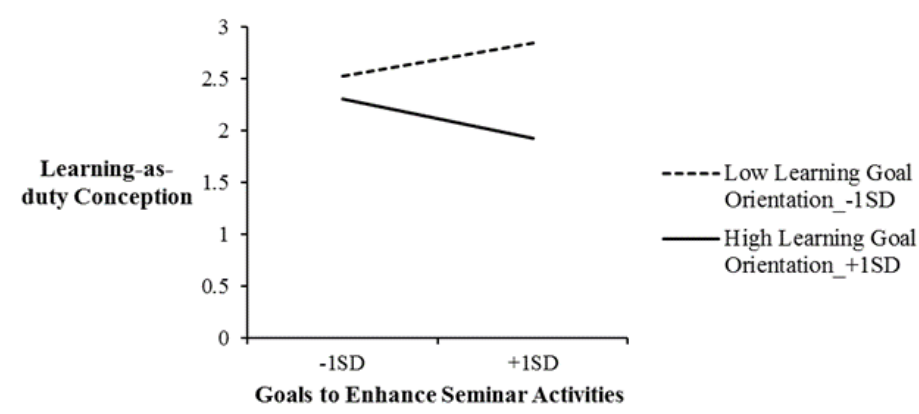

Figure 2(b). Interaction of Goals to Enhance Seminar Activities and Learning Goal Orientation predicting Learning-as-duty Conception

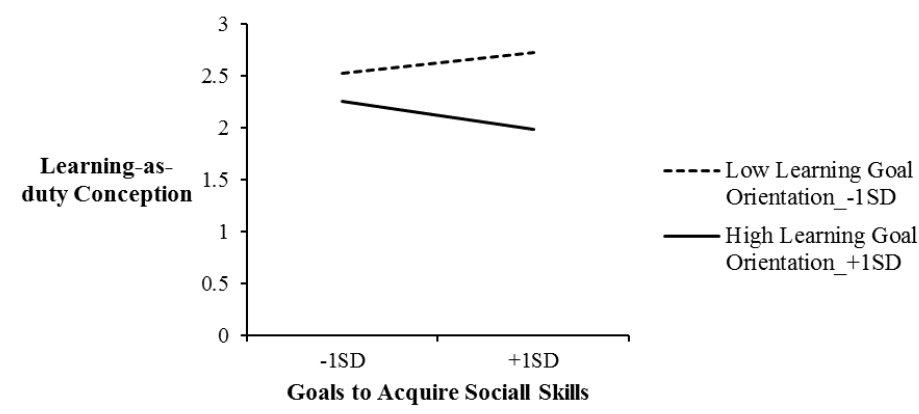

Figure 2(c). Interaction of Goals to Acquire Social Skills and Learning Goal Orientation predicting Learning-as-duty Conception

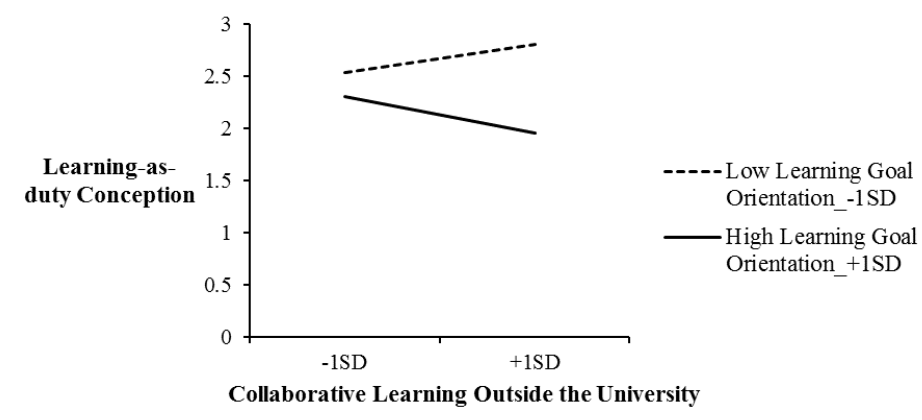

Figure 2(d). Interaction of Collaborative Learning Outside the University and Learning Goal Orientation predicting Learning-as-duty Conception

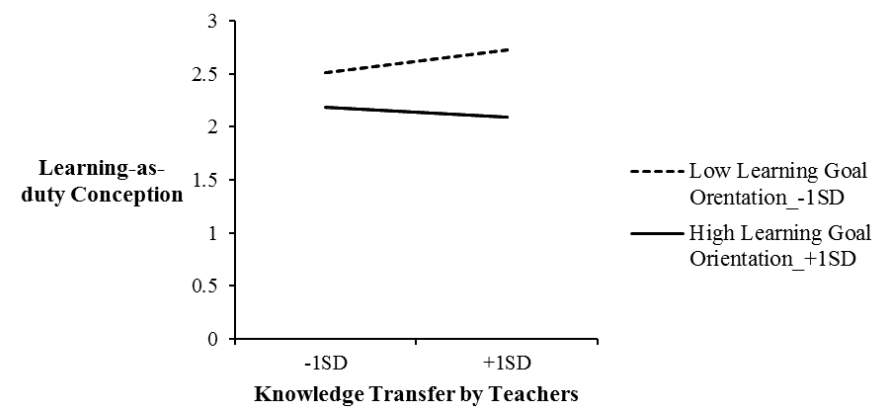

Figure 2(e). Interaction of Knowledge Transfer by Teachers and Learning Goal Orientation predicting Learning-as-duty Conception 


\section{DISCUSSION}

In this study, in order to clarify the effects of teachers' Educational Policy of the seminar on students' Learning-as-duty Conception, we examined the effects of interaction between teachers' Educational Policy and students' Learning Goal Orientation on Learning-as-duty Conception of the students. Since the interaction between teachers' Educational Policy of the seminar and students' Learning Goal Orientation showed a significant or a marginally significant for students' Learning-as-duty Conception in five analyses, in each of the analyses, a simple slope test was performed. The result suggested that the relationship between teachers' Educational Policy of the seminar and students' Learning-as-duty Conception may change depending on the level of students' Learning Goal Orientation. In the following discussion, the effects of teachers' Educational Policy of the seminar on students' Learning-as-duty Conception are discussed, divided into two case i.e., students with higher and lower Learning Goal Orientation.

Case in which the students have high Learning Goal Orientation

As a result of the simple slope test, in the seminar consisting of the students who have high Learning Goal Orientation, Goal to Enhance Seminar Activities, Goals to Acquire Social Skills, and Collaborative Learning Outside the University showed negative relationships with Learning-as-duty Conception. There was a significant positive correlation between Goals to Acquire Social Skills and Collaborative Learning Outside the University $(\mathrm{r}=.47, \mathrm{p}<01)$, meaning that teachers who aim to make students aware of social connections and acquire social skills tend to provide students with opportunities, i.e., they tried to let students experience off-campus collaborative learning. The teachers' Educational Policy, which focuses on emphasizing the acquisition of social skills and considers collaborative learning outside the university as seminar activities, would be effective only for students with high Learning Goal Orientation.

It was indicated that, in the seminar consisting of the students who have high Learning Goal Orientation, the more the teacher gives students the opportunity to experience collaborative learning outside the university, the lower the students' Learning-as-duty Conception becomes. Students who are oriented toward learning goals tend to select challenging tasks (Elliot \& Dweck 1988), not fearing taking risks (Printrich 2000), and to seek a challenge in learning. Learning outside the university is often unpredictable as to what will happen, therefore, it is likely to be exciting and challenging for the students. In collaborative learning, teachers are just facilitators, often allowing students to take initiative for classes. It is suggested that students with high Learning Goal Orientation are actively involved in challenging learning and recognize themselves as learners; and as a result, their Learning-as-duty Conception was suppressed.

\section{Case in which the students have low Learning Goal Orientation}

As a result of the simple slope test, in the seminar where the students have low Learning Goal Orientation, Understanding Student's Characteristics, Goals to Enhance Seminar Activities, Collaborative Learning Outside the University, and Knowledge Transfer by Teachers showed positive relationships with Learning-as-duty Conception. According to Fushikida et al. (2014), the more the teacher tries to understand the students' characteristics, the more they tend to improve seminar activities. In this study, there was a significant positive correlation between Understanding Students' Characteristics and Enhance Seminar Activities $(\mathrm{r}=.55, \mathrm{p}<01)$. Therefore, if the students have low Learning Goal Orientation, the teachers' Educational Policy, which consciously tries to understand students' characteristics and enhance activities in the seminar, may work as a negative factor as that increases students' Learning-as-duty Conception.

It was indicated that, in the seminar consisting of the students who have low Learning Goal Orientation, the more the teacher has the opportunity to transfer knowledge to the students, the higher students' Learning-as-duty Conception becomes. Students with low Learning Goal Orientation tend not to be interested in learning content (Printrich 2000). It is suggested that students with low Learning Goal Orientation are not interested in the content provided by the teacher in the seminar; therefore, when the teacher frequently intervenes, the students feel that they are being forced, with the result that their Learning-as-duty Conception may increase.

It was indicated that, in the seminar consisting of the students who have low Learning Goal Orientation, the more the teacher gives students the opportunity to experience collaborative learning outside the university, the higher the students' Learning-as-duty Conception becomes. Collaborative learning requires students to participate actively. Students with low Learning Goal Orientation are forced to take part in collaborative learning without their motivation, so their Learning-as-duty Conception may increase. 


\section{LIMITATION AND FUTURE WORK}

The limitation and the future work of this study are summarized as follows; The first is the generalization of the findings in this study. We need to be cautious in generalizing the suggestions obtained in the current study because the analysis is based on the data obtained from questionnaires from only 43 teachers. The second is that we did not take into consideration students' tendencies in the initial stage before the seminars started. It is not clear whether the responses among students in an individual seminar were consistent because the same types of students were gathered in the same seminar, or because they were educated by the same teacher. Perhaps both factors are involved. In future, it will be necessary to conduct a longitudinal survey before students are assigned to the seminars, and to conduct an analysis taking into account students' characteristics and environmental factors. The third is the elucidation of the process of how the students' Learnings-as-duty Conception is suppressed or increased. As shown in the discussion, we mentioned the process of how the students' Learnings-as-duty Conception is suppressed or increased, but it is not empirically evaluated. In order to make use of research findings in educational support, it is important to clarify the process.

\section{ACKNOWLEDGMENT}

This work was partially supported by JSPS KAKENHI Grant Number $18 \mathrm{H} 05320$.

\section{REFERENCES}

Ames, C., \& Archer, J. ,1987. Mothers'beliefs about the role of ability and effort in school learning. Journal of Educational Psychology, Vol.79, pp.409-414.

Ames, C., \& Archer, J. ,1988. Achievement goals in the classroom: Students'learning strategies and motivation process. Journal of Educational Psychology, Vol.80, pp.260-267.

Dart, Barry C., Burnett, Paul C., Purdie, Nola M., Boulton-Lewis, Gillian M., Campbell, Jenny, \& Smith, David ,2000. Students' conceptions of learning, the classroom environment and approaches to learning. The Journal of Educational Research, Vol.93, No.4, pp. 262-270.

Diener, C. I., \& Dweck, C. S. 1974. An analysis of learned helplessness: Continuous changes in performance, strategy, and achievement cognition following failure. Journal of Personality and Social Psychology, Vol.36, pp.451-462.

Elizabeth R. Peterson., Gavin T. L. Brown., S. Earl Irving, 2010. Secondary school students' conceptions of learning and their relationship to achievement. Learning and Individual Differences, Vol. 20, pp.167-176.

Elliot, A. J., \& Church, M. A.,1997. A hierarchical model of approach and avoidance achievement motivation. Journal of Personality and Social Psychology, Vol.72, pp.218-232.

Elliott, E. S., \& Dweck, C. S. ,1988. Goals: An approach to motivation and achievement. Journal of Personality and Social Psychology, Vol.54, No.1, pp.5-12.

Fushikida, W., Kitamura, S., \& Yamauchi, Y. ,2018. The effects of lesson structures in undergraduate seminars on growth in generic skills studies. Japan journal of educational technology, Vol.37, No. 4, pp.419-433.

Patrick Raymund James M. Garcia, Simon Lloyd D. Restubog, Lemuel S. Toledano, Laramie R. Tolentino, \& Alannah E. Rafferty, 2011. Differential Moderating Effects of Student- and Parent-Rated Support in the Relationship Between Learning Goal Orientation and Career Decision-Making Self-Efficacy. Journal of Career Assessment, Vol. 20, No.1, pp. 22-33.

Pintrich, P. R. ,2000. Multiple goals, multiple pathways: The role of goal orientation in learning and achievement. Journal of Educational Psychology, Vo.92, pp.544-555.

Takayama, S., 2002. The relationship between learning conception, it's Determinants and Learning Strategies. Memoirs of the Faculty of Education. Literature and Social science, Vol.37, pp.19-26.

Van Rossum, E. J., \& Schenk, S. M. ,1984. The relationship between learning conception, study strategy and learning outcome. British Journal of Educational Psychology, Vol.54, pp.73-83.

Walter D. Davis., Charles M. Carson., Anthony P. Ammeter., \& Darren C. Treadway., 2005. The Interactive Effects of Goal Orientation and Feedback Specificity on Task Performance. Human Performance, Vol. 18, No. 4, pp.409-426.

Yokoyama, M., \& Miwa, K. ,2018. Relationship between Goal Orientation, Conception of Learning and Learning Behavior. Proceedings of 15 th international conference of cognition and exploratory learning in digital age (CELDA 2018), pp.233-240. 